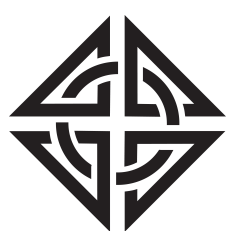

SCIENTIA
Sharif University of Technology

Scientia Iranica

Transactions A: Civil Engineering

http://scientiairanica.sharif.edu

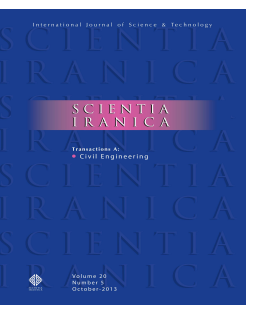

\title{
Experimental investigation of bond characteristics of deformed and plain bars in low strength concrete
}

\author{
S. Ahmad ${ }^{\mathrm{a}, *}$, K. Pilakoutas ${ }^{\mathrm{a}}$, M.M. Rafi ${ }^{\mathrm{b}}$, Q. Uz Zaman Khan ${ }^{\mathrm{c}}$, and K. Neocleous ${ }^{\mathrm{d}}$ \\ a. Department of Civil and Structural Engineering, University of Sheffield, Sheffield, United Kingdom. \\ b. Department of Civil Engineering, NED University of Engineering and Technology, Karachi, Pakistan. \\ c. Department of Civil Engineering, University of Engineering and Technology, Taxila, Pakistan. \\ d. Department of Civil and Geomatics Engineering, Cyprus University of Technology P.O. Box 50329, Lemesos 3603, Cyprus.
}

Received 7 February 2016; received in revised form 16 February 2017; accepted 23 October 2017

KEYWORDS
Low strength
concrete;
Normal strength
concrete;
Non-engineered
reinforced concrete;
Reinforced concrete;
Bond-slip;
Deformed bar;
Cold-formed bar;
Plain bar.

\section{Introduction}

Non-Engineered Reinforced Concrete (NERC) buildings in developing countries are known to be highly vulnerable to seismic motions [1]. Post-earthquake

\footnotetext{
*. Corresponding author. Tel.: +44 (0)114222 5065;

Fax: +44 (0)114222 5700

E-mail addresses: sohaibahmad@hotmail.com (S. Ahmad);

k.pilakoutas@sheffield.ac.uk (K. Pilakoutas);

rafi-m@neduet.edu.pk (M.M.Rafi);

dr.qaiser@uettaxila.edu.pk (Q.UzZaman Khan);

kyriacos.neocleous@cut.ac.cy (K. Neocleous)
}

doi: $10.24200 /$ sci.2017.4570 damage surveys done in developing countries [1-5] attribute the poor performance of Reinforced Concrete (RC) structures to the use of poor materials, bad design, detailing, and inappropriate construction practices [1-5]. Most of the collapsed RC structures in the Kashmir earthquake (2005), Pakistan, had an average concrete compressive strength $\left(f_{c}^{\prime}\right)$ of around $15 \mathrm{MPa}$. Bal et al. [5] tested cores taken from 1178 existing RC buildings, located in Istanbul and its surroundings, and reported a mean $f_{c}^{\prime}$ of $17 \mathrm{MPa}$. It is widely accepted that Low Strength Concrete (LSC) is one of the main reasons for many brittle failures in NERC. Even in developed countries such as Japan, post-earthquake studies after the Kobe Earthquake in 1995 reported 
many existing RC buildings to have very low concrete strength (less than $13.5 \mathrm{MPa}$ ), which is the basis of research for Hong and Araki [6].

Pull-out and splitting were commonly observed as bond failure modes during the Kashmir earthquake and became one of the causes of brittle failures in RC buildings, as shown by Ahmad [7]. The rebar slip in structural components due to bond failure is shown schematically in Figure 1(a) and (b). Moreover, reports by Chaudat et al. [8] and Pinho and Elanashai [9] regarding seismic testing of various low strength $\mathrm{RC}$ frames, designed according to old codes or construction practices, showed that insufficient lap splices and bond degradation were the predominant factors for strength and stiffness degradation of these structures at higher peak ground acceleration levels.

Pull-out and splitting failures depend on the shear and tensile strength of concrete, respectively. The

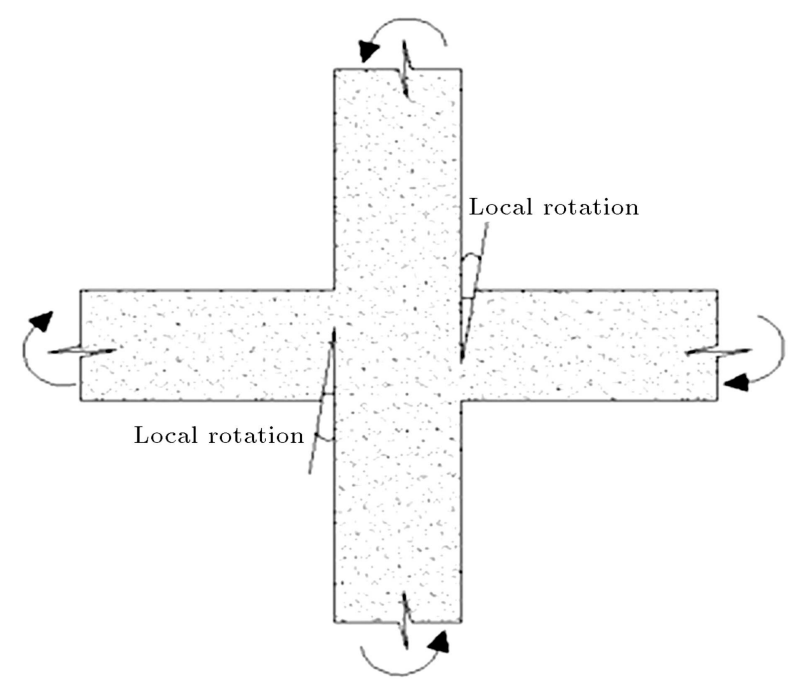

(a)

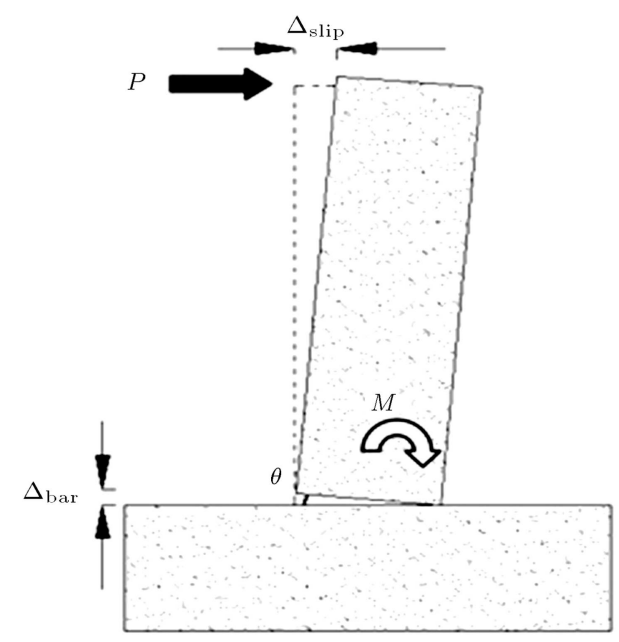

(b)

Figure 1. Bond related damages and detailing deficiencies: (a) Bar pull-out and (b) short lap splice. tensile and shear strength of concrete have a strong correlation to compressive strength less than 10000 psi (69 MPa), ACI408 [10]. The force is transferred mainly by bearing against the lugs, either exceeding the concrete tensile or shearing strength causing the failure to occur by tensile splitting or pull-out (shearing of concrete), respective1y. Splitting usually occurs due to lower concrete cover $\left(<2 d_{b}\right)$ and insufficient confinement, ACI408.2 [11]. When a bar moves with respect to concrete, splitting failure initiates due to the wedging action of ribs. Splitting is normally a critical bond failure mode for RC buildings and its capacity is lower than that for pull-out for a given anchorage length. Bar pull-out usually occurs in elements with enough confinement.

Bond performance is also related to rib geometry, and an increase in rib height can generally increase initial bond stiffness and enhance bond strength [10-11]. Transverse reinforcement resists splitting failure after cracking of a member, especially under cyclic loading, and provides confinement, which results in pull-out failure. Casting position and improper compaction also affect the bond strength [11]. The problem of improper compaction is quite significant in poorly constructed $\mathrm{RC}$ structures, where the voids and water pockets are formed due to plastic flow of concrete [11].

The bond-slip $(\tau-s)$ behaviour of different bar types used typically in LSC has not been studied much, and past vulnerability assessment studies by Kyriakides (2008) [12] had to assume that $\tau-s$ behaviour of rebars in LSC is similar to that of Normal Strength Concrete (NSC). Only a few studies examined this behaviour; for example, Mohamad and Clark [13] conducted pull-out tests on extremely LSC specimens $\left(200 \times 300 \times 300 \mathrm{~mm}\right.$ specimens with links and $f_{c}^{\prime} \sim$ $5 \mathrm{MPa}$ ) to evaluate $\tau_{\max }$ of both top and bottom cast deformed and plain bars with varying cover $(c)$ to bar diameter $\left(d_{b}\right)$ ratios. The typical LSC range for NERC buildings (10-15 MPa) was not considered, and pull-out tests were carried out by Feldman and Bartlett [14] using 16 and $32 \mathrm{~mm} d_{b}$ plain bars in LSC (12 to $14 \mathrm{MPa}$ ) to evaluate $\tau-s$ characteristics of plain bars with different roughness levels. Experimental results showed an average slip value of $0.01 \mathrm{~mm}$ at $\tau_{\max }$. The reported average value of $\tau_{\max }$ ranges from 0.98 to $2.2 \mathrm{MPa}$ for different roughness levels. The effects of smaller cover, shorter development lengths, and other bar types on $\tau-s$ behaviour were not studied. More recently, Bedirhanoglu [15] carried out cyclic tests on 9 exterior beam-column joints made of LSC concrete $(<10 \mathrm{MPa})$ using plain bars. The mean $\tau_{\max }$ was found to be varying between $0.33 \sqrt{f_{c}^{\prime}}$ and $0.5 \sqrt{f_{c}^{\prime}} \mathrm{MPa}$. Hong and Araki [6] conducted pull-out tests under load reversal to study the bond characteristics of plain round bars having 13, $19 \mathrm{~mm}$ diameters and embedment length of $10 d_{b}$ in LSC (11.2 MPa). The maximum bond stresses 
of the specimens were less than the allowable stress in RC Codes of Japan Architectural Institute for the longterm load, and that the degradation of bond stress was apparently found to be influenced by the loading cycles. The average bond strength values include $0.33 \mathrm{MPa}$ and $0.32 \mathrm{MPa}$ for 13 and $19 \mathrm{~mm} d_{b}$, respectively.

The main aim of conducting the current research work is to investigate the bond characteristics of typically used steel bars in NERC/ existing RC structures by considering various deficient parameters and to develop bond strength relations for low strength concrete $\leq 15 \mathrm{MPa}$. Previous researches have not accounted for the considered deficient parameters and have not provided a multi-variable bond strength equation for low strength concrete $<15 \mathrm{MPa}$. This paper initially presents the results of experiments undertaken on pullout and splitting specimens. The main parameters of the study included low strength concrete, rebar type, diameter, concrete cover, and embedment length. The statistical variation of the experimental data is presented, and the bond performance of different bar types is discussed. The paper finally presents development of bond strength models for different bar types in LSC using the current experimental data.

\section{Experimental programme}

The experimental programme is planned to study pullout and splitting bond failure modes in LSC under monotonic loading. This experimental work is part of research work conducted by Ahmad [16], and Ahmad et al. [17] developed an analytical seismic vulnerability assessment framework for reinforced concrete structures in developing countries. All the tested specimens were unconfined and made of plain concrete. The main parameters included $L S C(\sim 15 \mathrm{MPa})$, bar development length $\left(L_{d}\right)$, concrete cover $(c)$, rebar type, and diameter $\left(d_{b}\right)$. Pull-out and splitting tests have been conducted in a specially designed rig. The pull-out and splitting experiments are designed so as to include the effect of different deficient parameters observed in the post-Kashmir earthquake surveys and are more important for bond-slip of reinforcement behaviour in RC structures of developing countries. Most common steel bars types used in old and new constructions of
RC structures in Pakistan are used in experiments. Low strength concrete mix design is used to prepare pull-out and splitting specimens. These specimens with varying development lengths, cover, bar type, and sizes are tested in the testing setup. Mechanical properties of different steel bars and the LSC used are described in the following section.

\subsection{Steel bars}

Two different types of steel bars were used in the experimental programme, with different surface deformations and diameters. These bars include hot-rolled deformed (def.) and plain bars. Mechanical characteristics of different types of steel bars are presented in Tables 1. Table 2 gives the rib details of the deformed bar used in the tests, and Figure 2 shows the bar pattern schematically.

\subsection{Concrete}

Since the concrete compressive strength for the majority of NERC structures falls between 8 and $15 \mathrm{MPa}$, the LSC mix proportions mentioned in Table 3 were used to cast all the pull-out and splitting specimens. The compressive strength was determined according to BS1881-121 [18] by casting $100 \mathrm{~mm} \times 200 \mathrm{~mm}$ cylinders from the mix. Indirect splitting tests in accordance with BS:EN12390-6 [19] were also carried out to evaluate the tensile strength of concrete specimens. The

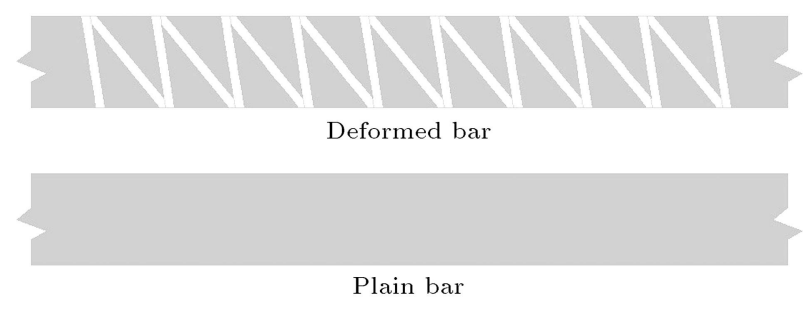

Figure 2. Schematic diagrams of different bars with rib patterns.

Table 2. Rib details of deformed bars.

\begin{tabular}{ccc}
\hline $\begin{array}{c}\text { Bar diameter } \\
(\mathbf{m m})\end{array}$ & $\begin{array}{c}\text { Rib spacing }(\boldsymbol{s}) \\
(\mathbf{m m})\end{array}$ & $\begin{array}{c}\text { Rib height }(\boldsymbol{h}) \\
(\mathbf{m m})\end{array}$ \\
\hline 12 & 13 & 2 \\
16 & 17 & 2 \\
\hline
\end{tabular}

Table 1. Mechanical properties of bars.

\begin{tabular}{ccccccc}
\hline $\begin{array}{c}\text { Bar } \\
\text { type }\end{array}$ & $\begin{array}{c}\text { Bar } \\
\text { diameter } \\
(\mathbf{m m})\end{array}$ & $\begin{array}{c}\text { Young's } \\
\text { modulus } \\
(\mathbf{G P a})\end{array}$ & $\begin{array}{c}\text { Yield } \\
\text { strength } \\
\mathbf{( M P a )}\end{array}$ & $\begin{array}{c}\text { Ultimate } \\
\text { strength } \\
(\mathbf{M P a})\end{array}$ & $\begin{array}{c}\text { Strain at } \\
\text { yielding } \\
(\boldsymbol{\%})\end{array}$ & $\begin{array}{c}\text { Ultimate } \\
\text { strain } \\
(\boldsymbol{\%})\end{array}$ \\
\hline Def. & 12 & 206 & 472 & 609 & 0.23 & 1.9 \\
Def. & 16 & 200 & 479 & 579 & 0.24 & 1.7 \\
Plain & 12 & 197 & 315 & 359 & 0.16 & 0.73 \\
Plain & 16 & 201 & 323 & 387 & 0.16 & 0.86 \\
\hline
\end{tabular}


Table 3. Details of the various mixes used for making LSC.

\begin{tabular}{cccccc}
\hline $\begin{array}{c}\text { Cement (C) } \\
\left(\mathbf{k g} / \mathbf{m}^{\mathbf{3}}\right)\end{array}$ & $\begin{array}{c}\text { Sand (S) } \\
\left(\mathbf{k g} / \mathbf{m}^{\mathbf{3}}\right)\end{array}$ & $\begin{array}{c}\text { Aggregate (A) } \\
\left(\mathbf{k g} / \mathbf{m}^{\mathbf{3}}\right)\end{array}$ & w/c & C:S:A & $\begin{array}{c}\text { Curing } \\
(\text { days })\end{array}$ \\
\hline 313 & 619 & 1188 & 0.75 & $1: 2: 3.8$ & 5 \\
\hline
\end{tabular}

mean $(\mu)$ and $(\sigma)$ standard deviation values of means $f_{c}^{\prime}$ and $f_{c t}$ of the pull-out and splitting specimens are listed in Table 4.

\subsection{Test arrangement}

The test setup, including test rig and instrumentation, used for conducting pull-out and splitting tests is shown schematically in Figure 3(a). A $10 \mathrm{~mm}$ rubber plate was placed on the specimen's top face to ensure an even pressure and minimum confinement on the concrete surface. The reaction plate of the rig has appropriate holes, so that the LVDTs can pass through. A mounting rig was used for holding two LVDTs (for the splitting tests) or three LVDTs (for the pull-out tests) at the loaded end (L.E.) of the specimen, and the mounting rig was clamped with screws on the bar (see Figure 3(b)). A small metal (aluminum) angle was glued on the unloaded end (U.L.E.) of each specimen to mount an LVDT. This transducer was positioned at the centre of the bar and was used to measure the unloaded end slip. This arrangement corresponds to RILEM/CEB/FIP [20] in which the bonded length is located at the end of the specimen to avoid conical failures near the loaded end. Examples of pull-out and splitting specimen in testing rig are shown in Figure 3(c) and (d), respectively.

\subsection{Specimen's details for pull-out and splitting tests}

2.4.1. Pull-out tests

Pull-out cube specimens with two bar types and three different development lengths, i.e., $5 d_{b}, 10 d_{b}$, and $15 d_{b}$,

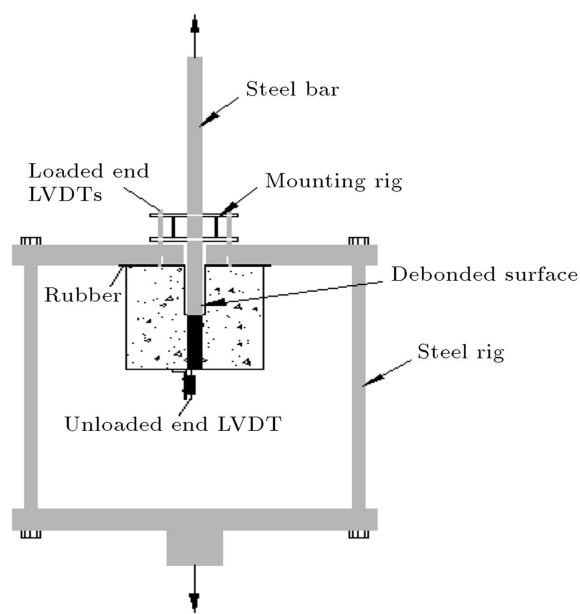

(a)

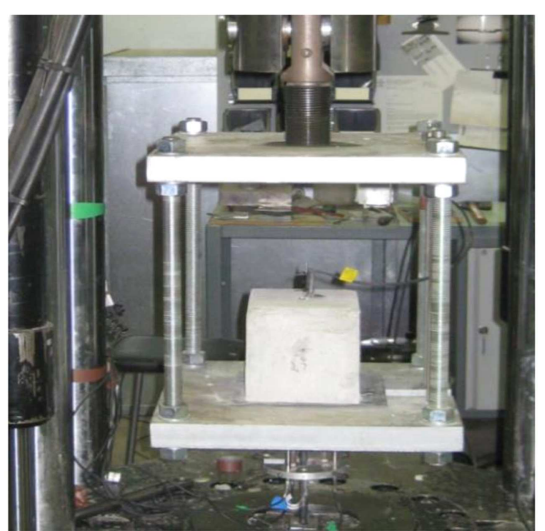

(c)

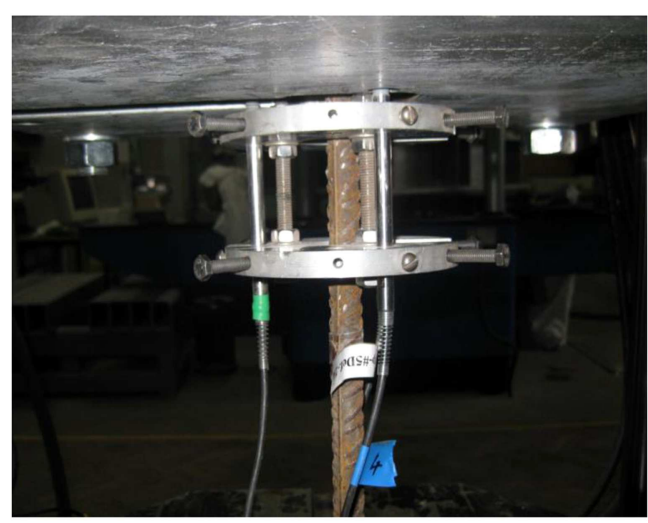

(b)

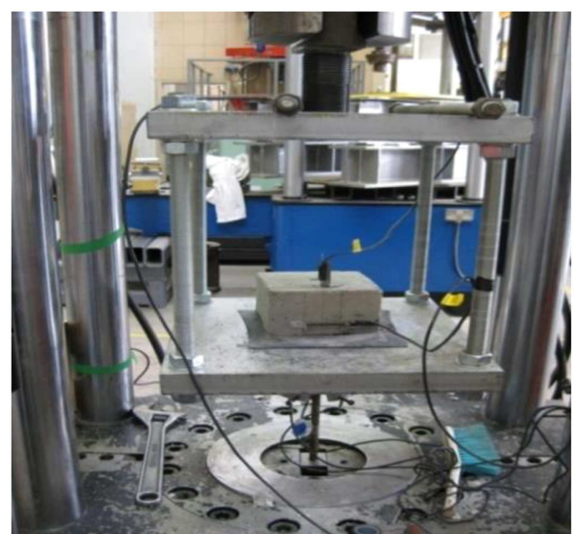

(d)

Figure 3. Test setup adopted for experiments: (a) Cross-sectional view of pull-out rig with specimens and instrumentation, (b) smaller mounting rig with LVDTs at loaded end, (c) rig for splitting tests, and (d) side splitting of plain bar specimen. 
Table 4. Mean compressive and tensile concrete strength for pull-out and splitting specimens.

\begin{tabular}{ccccc}
\hline Specimens & $\begin{array}{c}\boldsymbol{f}_{c}^{\prime}, \boldsymbol{\mu} \\
(\mathrm{MPa})\end{array}$ & $\begin{array}{c}\boldsymbol{\sigma} \\
(\mathrm{MPa})\end{array}$ & $\begin{array}{c}\boldsymbol{f}_{c t}, \boldsymbol{\mu} \\
(\mathbf{M P a})\end{array}$ & $\begin{array}{c}\boldsymbol{\sigma} \\
(\mathbf{M P a})\end{array}$ \\
\hline Pull and splitting & 14.5 & 1.89 & 2.66 & 0.31 \\
\hline
\end{tabular}

were tested. The details of the bar size, type, specimen size, and embedment lengths used for making pull-out specimens are shown in Figures $4(\mathrm{a})$ and 5(a). For $L_{d}$ more than $150 \mathrm{~mm}, 150 \mathrm{~mm}$ (diameter) $\times 300 \mathrm{~mm}$ (height) cylinders were used. Cubic and cylinder pullout specimens are shown in Figures 4(b) and 5(b), respectively. Bars were debonded with two layers of cling film and PVC tape to achieve the desired embedment length. The bars were cut to $500 \mathrm{~mm}$ to fit the testing apparatus.

To measure the loaded end slip for pull-out specimens, three transducers were placed in a radius of $50 \mathrm{~mm}$ from the centre of the bar. These transducers were mounted on a small rig at an angle of 120 degree from each other. The schematic arrangement of the LVDTs positioned over the specimen surface is shown in Figure 6.

All the tests were displacement controlled, and
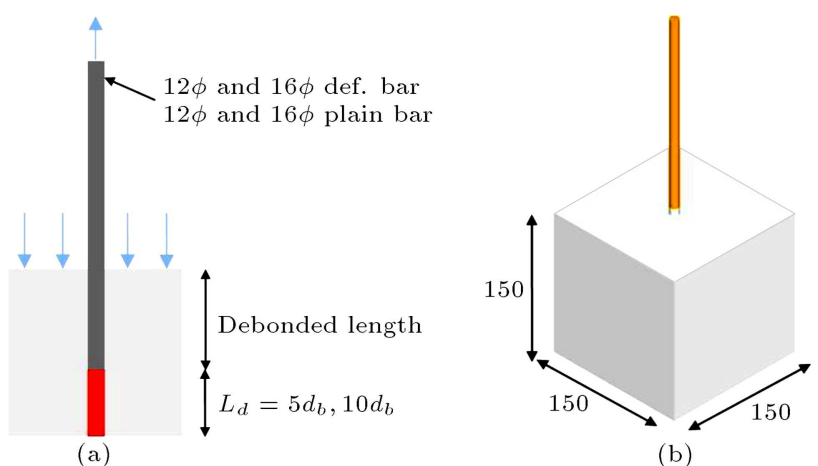

Figure 4. Pull-out cube specimens with varying bar sizes, types, and embedment lengths.

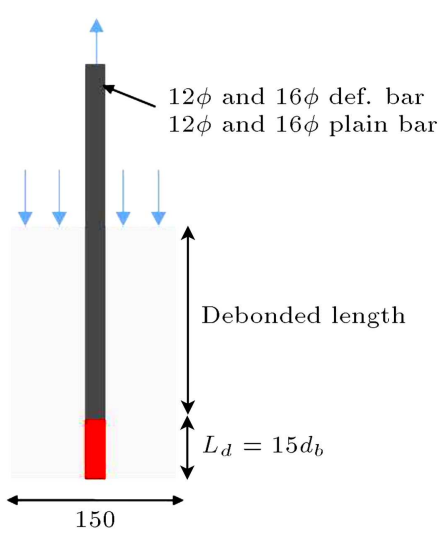

(a)

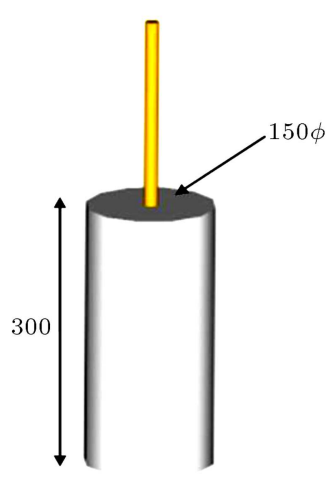

(b)
Figure 5. Pull-out cylinder specimens with varying bar sizes, types, and embedment lengths. the displacement rate was set to $0.5 \mathrm{~mm} / \mathrm{min}$. The used LVDTs had a maximum range of $10 \mathrm{~mm}$, and the data record stopped when the slip reached between 8 and $10 \mathrm{~mm}$. The bar was then pulled out completely at a faster rate. A typical rebar after pull-out is shown in Figure 7.

\subsubsection{Splitting tests}

In the splitting test specimens, bars were positioned eccentrically using varying concrete covers (i.e., $c=$ $\left.0 d_{b}, 1 d_{b}, 2 d_{b}\right)$ with reference to the concrete edge as shown in Figure 8(a) and (b) to achieve splitting failure mode. The embedment length in all the splitting specimens was $5 d_{b}$, and the specimens were cast up to the same height. The bars were cut to $500 \mathrm{~mm}$ to fit the testing apparatus.

The average of the displacements from three

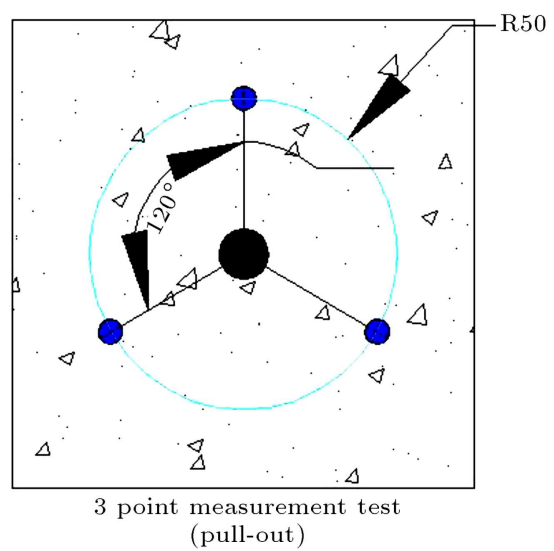

Figure 6. LVDTs arrangement in rig at the loaded end (pull-out test).

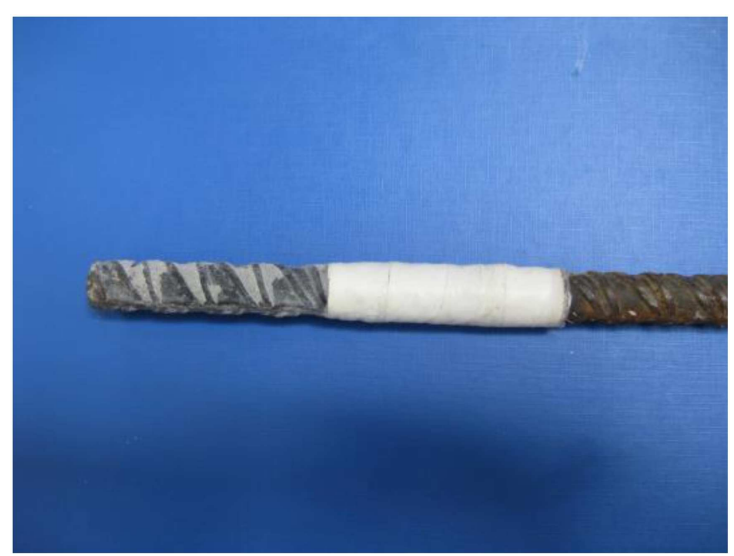

Figure 7. Steel reinforcing bar after pull-out test. 


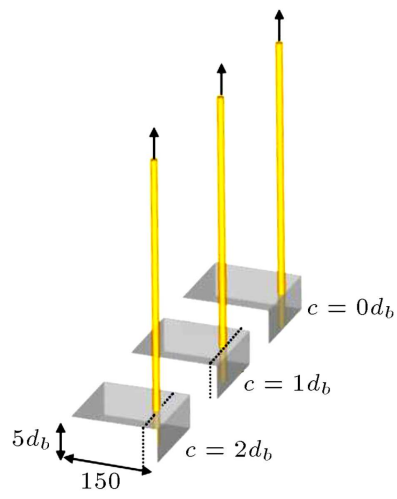

(a)

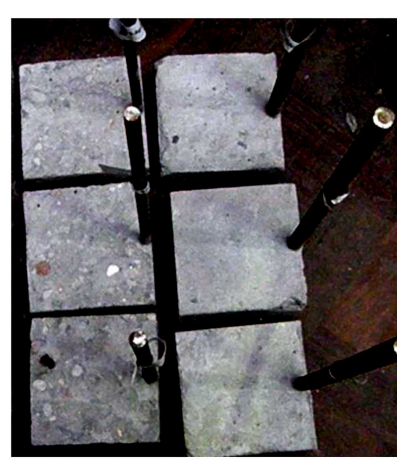

(b)
Figure 8. Splitting specimens with varying covers $\left(c=0 d_{b}, 1 d_{b}, 2 d_{b}\right)$.

transducers was used to eliminate possible bending of the bar. The loaded and unloaded end slips for the splitting specimens having $c=2 d_{b}$ were measured using the same LVDT arrangement as used for pullout tests (Figure 6), whereas loaded end slip for the specimens, having $c=0 d_{b}$ and $1 d_{b}$, was measured by making a two-point arrangement of the LVDT's at the loaded end, as shown in Figure 9(a) and (b). This arrangement was necessary due to the lack of space for the third LVDT.

The splitting specimens with varying concrete covers after splitting are shown in Figure 10(a)-(c), respectively.

\section{Experimental results}

Representative results for the deformed and plain bar pull-out specimens, having $d_{b}=12 \mathrm{~mm}$ and $L_{d}=$ $5 d_{b}$, are shown in Figure $11(\mathrm{a})$ and (b). U.L.E. and L.E. represent the unloaded and loaded end bondslip curves, respectively. The L.E. slip values are determined from the average slip measurements, done by either 2 or 3 LVDTs, minus the calculated extension of the bar outside the embedment length.

The deformed bars in general showed low bond strength for concrete with $f_{c}^{\prime}<10 \mathrm{MPa}$. For plain bars, the slip corresponding to bond strength is very low and the load-slip curve decays gradually.

Typical results for the deformed and plain bars splitting specimens having $d_{b}=12 \mathrm{~mm}, L_{d}=5 d_{b}$,

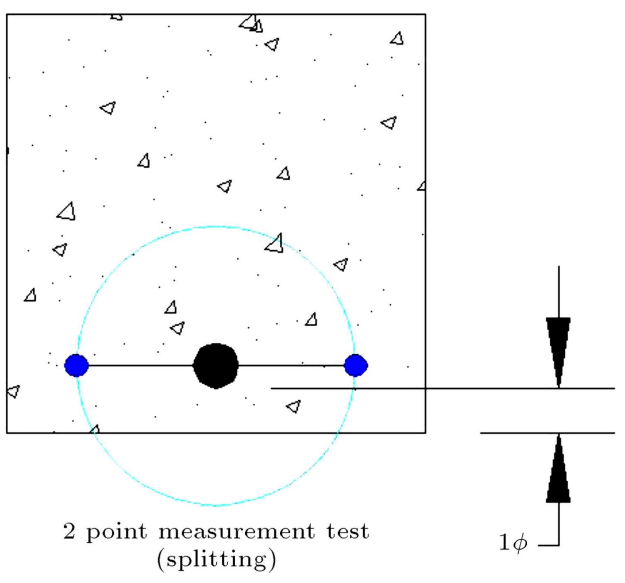

(a)

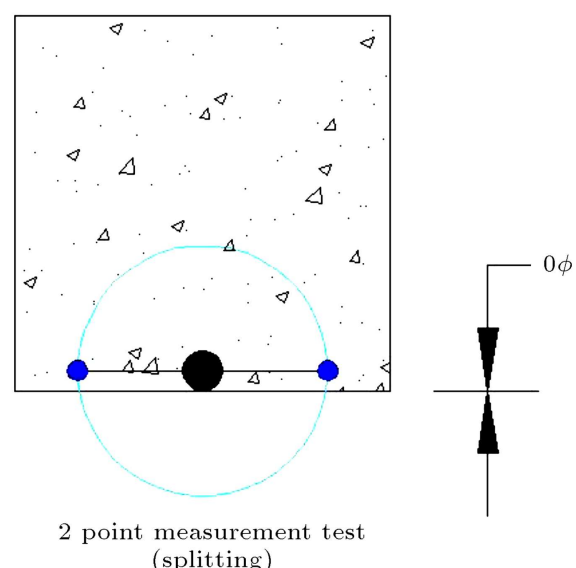

(b)

Figure 9. Two point LVDT's arrangement in the rig at the loaded end of splitting test specimens: (a) Specimens with $c=1 \mathrm{db}$ and (b) specimens with $c=0 \mathrm{db}$.

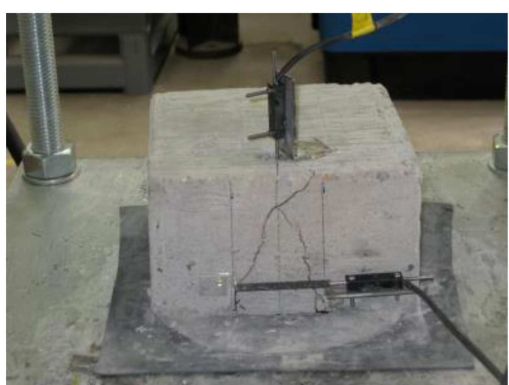

(a)

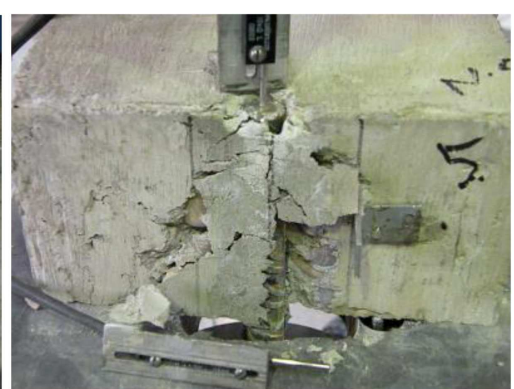

(b)

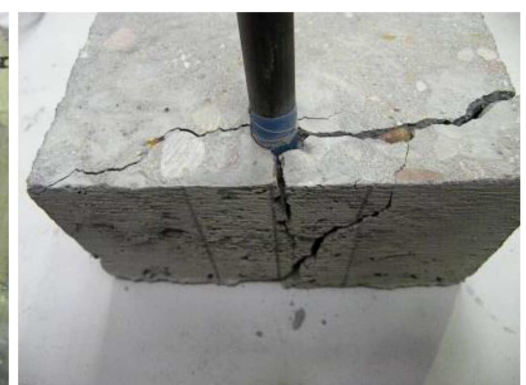

(c)

Figure 10. Splitting specimen with different failure modes: (a) V-notch splitting $c=1 d_{b}$, (b) exposed bar $c=0 d_{b}$, and (c) side splitting $c=1 d_{b}$. 


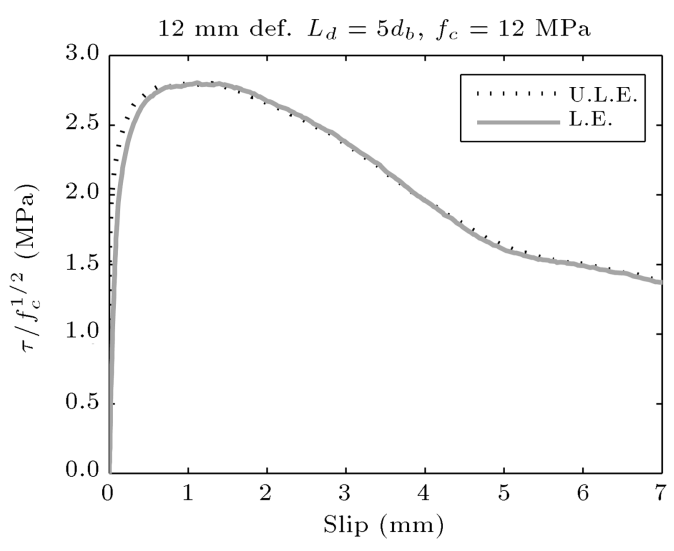

(a)

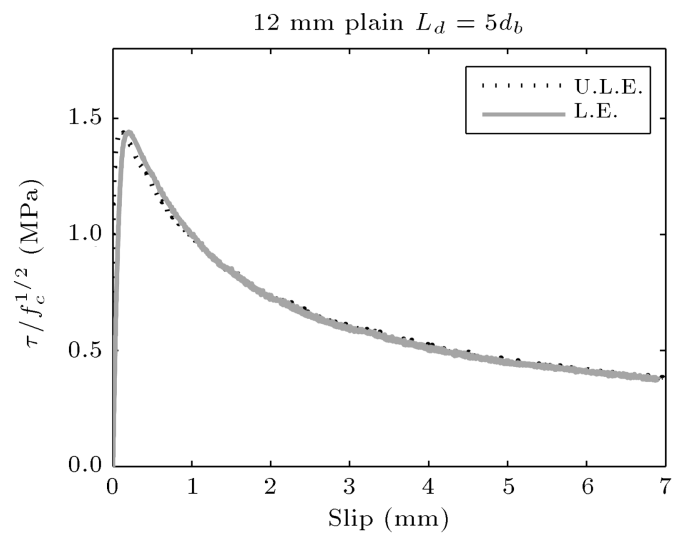

(b)

Figure 11. Typical bond-slip curves from pull-out tests: (a) $12 \mathrm{~mm}$ deformed and (b) $12 \mathrm{~mm}$ plain.

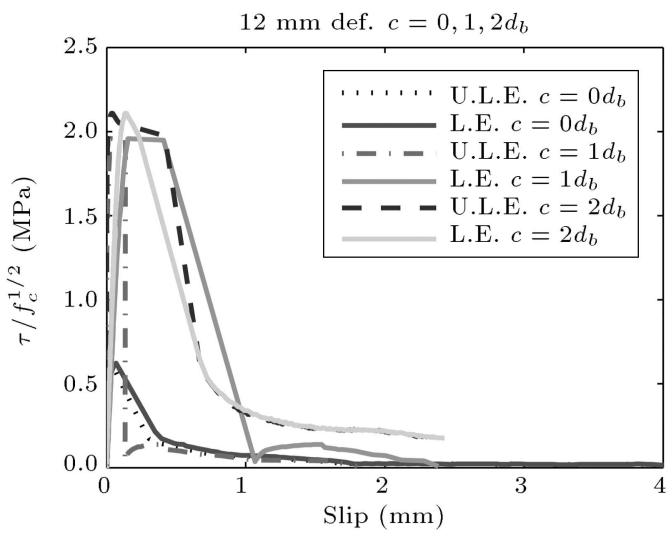

(a)

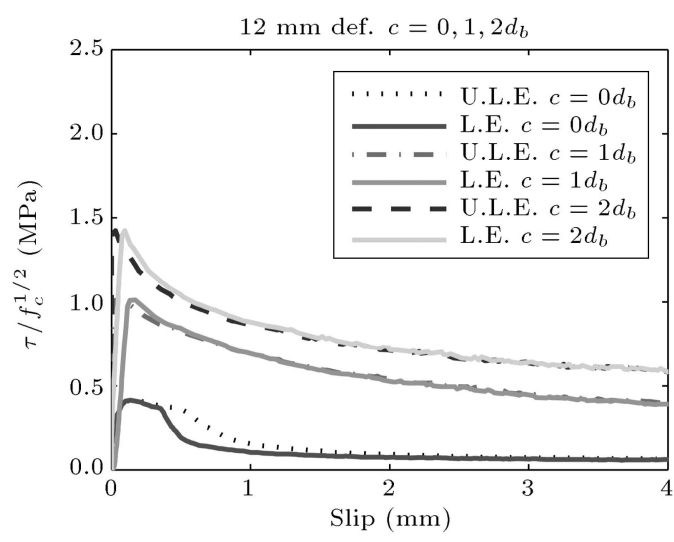

(b)

Figure 12. Typical bond-slip curves from splitting tests: (a) Deformed $\left(c=0,1,2 d_{b}\right)$ and (b) plain $\left(c=0,1,2 d_{b}\right)$.

and $c=0-2 d_{b}$ are shown in Figure $12(\mathrm{a})$ and (b), respectively. The value of $c=0$ represents extremely small concrete cover and practically represents exposed reinforcement condition in beams or columns typically observed in developing countries due to poor construction practices.

Deformed bar split specimens with extremely small cover showed a very low $\tau_{\max }$ at a small slip value. The bond strength increased by almost four times for curves $c=1$ and $2 d_{b}$ (Figure $12(\mathrm{a})$ ). For plain bar's split specimens $\left(d_{b}=12 \mathrm{~mm}\right)$, splitting did not occur in all cases. A few specimens with $c=0$ and $c=1 d_{b}$ showed brittle behaviour; however, most of the specimens, especially with covers 1 and $2 d_{b}$, showed a gradual decay of the load slip curve, as shown in Figure 12(b).

\section{Direct comparison and statistical analysis}

\subsection{Pull-out specimens}

A summary of results of tests along with the average results for each set of variables is presented in Table 5.
The concrete strength effect on bond is traditionally taken into account by normalizing $\tau_{\max }$ with respect to $\sqrt{f_{c}^{\prime}}$. This use of $\sqrt{f_{c}^{\prime}}$ for normalization has been proved to be effective up to concrete strengths of $55 \mathrm{MPa}$ (ACI408 (2003)).

The bar chart in Figure 13 shows the mean values of $\tau_{\max } / \sqrt{f_{c}^{\prime}}$ for deformed and plain bar specimens with different development lengths.

\section{Bond strength scatter for pull-out specimens}

Figure 14(a) shows the results of pull-out tests for the specimens with deformed bars of 12 and $16 \mathrm{~mm}$ diameters and $L_{d}=5 d_{b}$. All these specimens had low concrete strength $(\sim 10$ to $15 \mathrm{MPa})$. Bond strength of specimens having concrete strength of around $10 \mathrm{MPa}$ is found to be almost half the bond strength of specimens with relatively higher concrete strength $(\sim 15$ $20 \mathrm{MPa}$ ). The failure of most specimens with $L_{d}=10$ and $15 d_{b}$ was found to be either due to bar yielding or concrete splitting.

For plain bars, a lower variation can be seen (Figure 14(b)) in the results as compared to the 
Table 5. Summary of the pull-out tests using averages for each set of variables.

\begin{tabular}{ccccccccc}
\hline $\boldsymbol{d}_{\boldsymbol{b}}$ & Bar type & $\boldsymbol{L}_{\boldsymbol{d}}$ & $\boldsymbol{n}^{*}$ & $\boldsymbol{f}_{\boldsymbol{c}}^{\prime}$ & $\boldsymbol{\tau}_{\max }$ & $\boldsymbol{\tau}_{\max } / \sqrt{\boldsymbol{f}_{\boldsymbol{c}}^{\prime}}$ & $\boldsymbol{\tau}_{\max } / \sqrt{\boldsymbol{f}_{\boldsymbol{c}}^{\prime}}$ & $\boldsymbol{\tau}_{\max } / \sqrt{\boldsymbol{f}_{\boldsymbol{c}}^{\prime}}$ \\
\cline { 6 - 8 }$(\mathbf{m m})$ & & $(\mathbf{m m})$ & & $(\mathbf{M P a})$ & $\boldsymbol{\mu}(\mathbf{M P a})$ & $\boldsymbol{\mu}\left(\mathbf{M P a}^{\mathbf{1} \mathbf{2}}\right)$ & $\boldsymbol{\sigma}\left(\mathbf{M P a}^{\mathbf{1 / 2}}\right)$ & $\mathbf{C O V}$ \\
\hline 12.75 & Def. & 64 & 5 & 14.7 & 14.3 & 3.72 & 0.324 & 0.087 \\
12.75 & Def. & 64 & 3 & 9.2 & 7.8 & 2.55 & 0.397 & 0.155 \\
12.75 & Def. & 64 & 3 & 12.5 & 9.9 & 2.79 & 0.247 & 0.088 \\
12.75 & Def. & 128 & 4 & 15.0 & 7.7 & 1.99 & 0.667 & 0.335 \\
12.75 & Def. & 128 & 3 & 10.0 & 6.3 & 1.98 & 0.283 & 0.142 \\
17 & Def. & 191 & 3 & 15.0 & 7.8 & 2.01 & 0.009 & 0.004 \\
17 & Def. & 85 & 3 & 15.0 & 11.3 & 2.91 & 0.480 & 0.160 \\
17 & Def. & 170 & 3 & 15.0 & 11.9 & 3.08 & 0.072 & 0.023 \\
12 & Def. & 255 & 3 & 15.0 & 8.9 & 2.30 & 0.106 & 0.046 \\
12 & Plain & 60 & 4 & 15.5 & 6.0 & 1.52 & 0.147 & 0.097 \\
12 & Plain & 120 & 5 & 16.2 & 6.4 & 1.59 & 0.143 & 0.090 \\
16 & Plain & 180 & 3 & 15.0 & 4.7 & 1.22 & 0.192 & 0.157 \\
16 & Plain & 80 & 5 & 14.8 & 6.7 & 1.74 & 0.166 & 0.095 \\
16 & Plain & 160 & 3 & 15.0 & 5.9 & 1.52 & 0.013 & 0.009 \\
\hline
\end{tabular}

${ }^{*} n$ is the number of tested specimens.

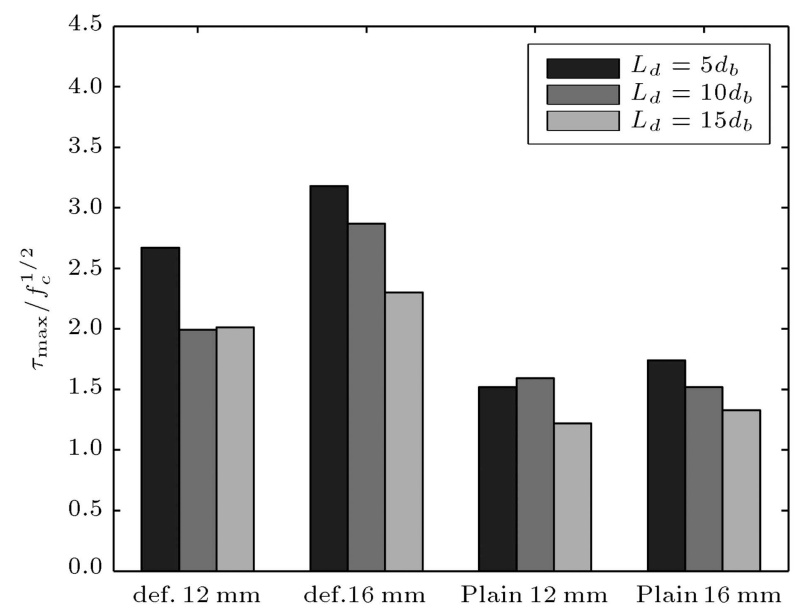

Figure 13. Mean normalized $\tau_{\max }$ of different bar types and sizes (pull-out specimens).

deformed bars (Figure 14(a)). As expected, an overall reduction in normalized $\tau_{\max }$ is evident with larger $L_{d}$.

\subsection{Splitting specimens}

Table 6 presents a summary of results of splitting tests, and the bar chart in Figure 15 shows the mean value of $\tau_{\max } / \sqrt{f_{c}^{\prime}}$ for specimens tested for the splitting failure mode. This includes 13 and $17 \mathrm{~mm}$ def and 12 and $16 \mathrm{~mm}$ plain bars having $L_{d}=5 d_{b}$ and varying concrete covers.

\section{Bond strength scatter for split specimens}

Figure 16(a) shows that, for $c / d_{b}=0$, the normalized $\tau_{\max }$ value for both diameters of deformed bar are

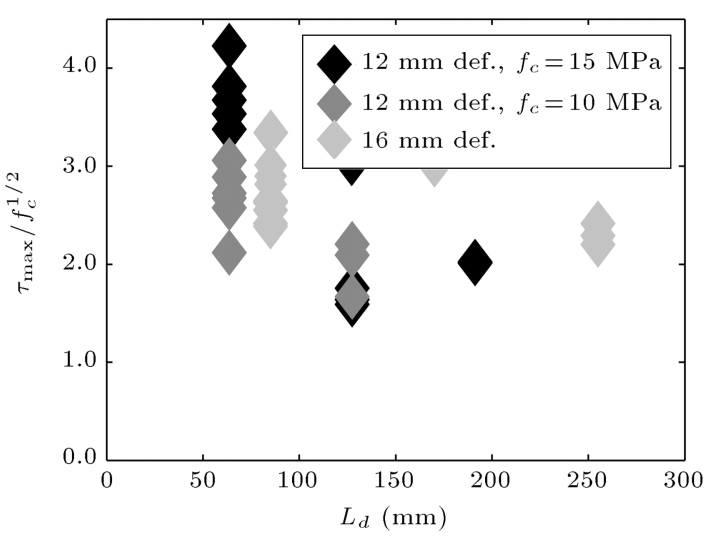

(a)

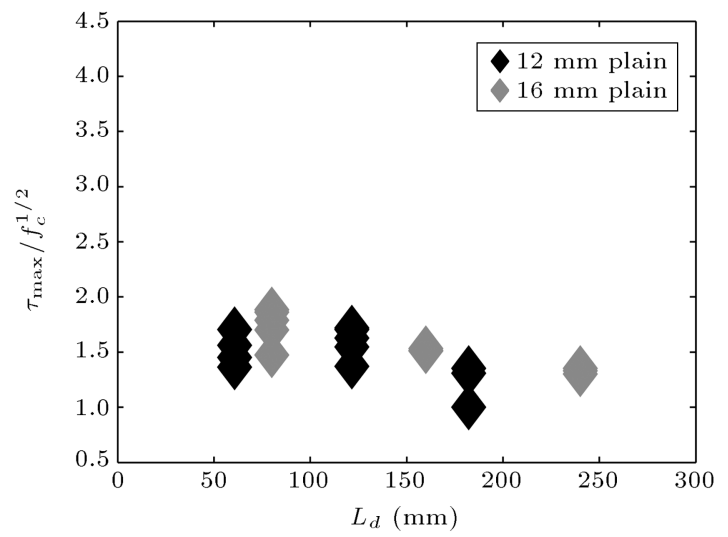

(b)

Figure 14. Normalized $\tau_{\max }$ at different development lengths for different bar types and sizes: (a) Deformed and (b) plain (pull-out specimens). 
Table 6. Summary of the splitting tests using averages for each set of variables.

\begin{tabular}{|c|c|c|c|c|c|c|c|c|c|}
\hline $\begin{array}{c}d_{b} \\
(\mathrm{~mm})\end{array}$ & Bar type & $\begin{array}{c}\text { Cover } c \\
(\mathrm{~mm})\end{array}$ & $c / d_{b}$ & $n$ & $\begin{array}{c}f_{c}^{\prime} \\
(\mathrm{MPa})\end{array}$ & $\begin{array}{c}\tau_{\max } \\
(\mathrm{MPa})\end{array}$ & $\begin{array}{c}\tau_{\max } / \sqrt{f_{c}^{\prime}} \\
\mu\left(\mathrm{MPa}^{1 / 2}\right)\end{array}$ & $\begin{array}{c}\tau_{\max } / \sqrt{f_{c}^{\prime}} \\
\sigma\left(\mathrm{MPa}^{1 / 2}\right)\end{array}$ & $\frac{\tau_{\max } / \sqrt{f_{c}^{\prime}}}{\mathrm{COV}}$ \\
\hline 12.75 & Def. & 26 & 2.0 & 3 & 15.0 & 6.3 & 1.64 & 0.201 & 0.123 \\
\hline 12.75 & Def. & 13 & 1.0 & 3 & 15.0 & 6.3 & 1.62 & 0.139 & 0.086 \\
\hline 12.75 & Def. & 0 & 0.0 & 5 & 15.0 & 1.9 & 0.48 & 0.118 & 0.244 \\
\hline 17 & Def. & 34 & 2.0 & 3 & 15.0 & 3.9 & 1.00 & 0.138 & 0.138 \\
\hline 17 & Def. & 17 & 1.0 & 3 & 15.0 & 3.8 & 0.98 & 0.058 & 0.059 \\
\hline 17 & Def. & 0 & 0.0 & 3 & 15.0 & 2.8 & 0.72 & 0.044 & 0.062 \\
\hline 12.75 & Plain & 26 & 2.0 & 3 & 15.0 & 5.7 & 1.47 & 0.077 & 0.052 \\
\hline 12.75 & Plain & 13 & 1.0 & 3 & 15.0 & 3.9 & 1.01 & 0.105 & 0.104 \\
\hline 12.75 & Plain & 0 & 0.0 & 3 & 15.0 & 1.8 & 0.46 & 0.081 & 0.175 \\
\hline 17 & Plain & 34 & 2.0 & 3 & 15.0 & 4.9 & 1.26 & 0.199 & 0.158 \\
\hline 17 & Plain & 17 & 1.0 & 3 & 15.0 & 3.2 & 0.83 & 0.054 & 0.066 \\
\hline 17 & Plain & 0 & 0.0 & 3 & 15.0 & 1.8 & 0.46 & 0.055 & 0.119 \\
\hline
\end{tabular}

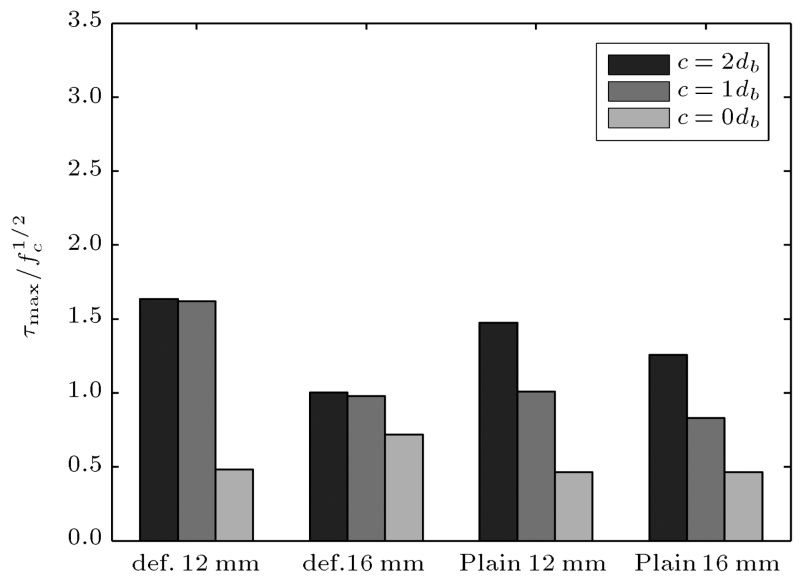

Figure 15. Mean normalized $\tau_{\max }$ of different bars types and sizes with varying covers (splitting specimens).

significantly lower than that for $c / d_{b}=1$ and 2 , highlighting the severity of the problem when proper cover is not maintained. In general, the splitting strength increases from $c / d_{b}=1$ to 2 for both bar sizes. Nonetheless, the $16 \mathrm{~mm}$ bar shows lower results than the $12 \mathrm{~mm}$ bar, indicating that bar diameter also affects the splitting strength.

No splitting was observed in the plain bar specimens, meaning that bar roughness is the dominant factor that mobilizes the friction between the bar and the concrete to give bond strength. As a result, a lower variability was obtained in the results of plain bars (Figure 16(b)). However, the value of normalized $\tau_{\max }$ for the plain bars clearly increases with the increase of $c / d_{b}$ ratio for both 12 and $16 \mathrm{~mm}$ diameters, as shown in Figure 16(b). This means that the cover thickness leads to increased confinement and, as a result, increases frictional resistance.

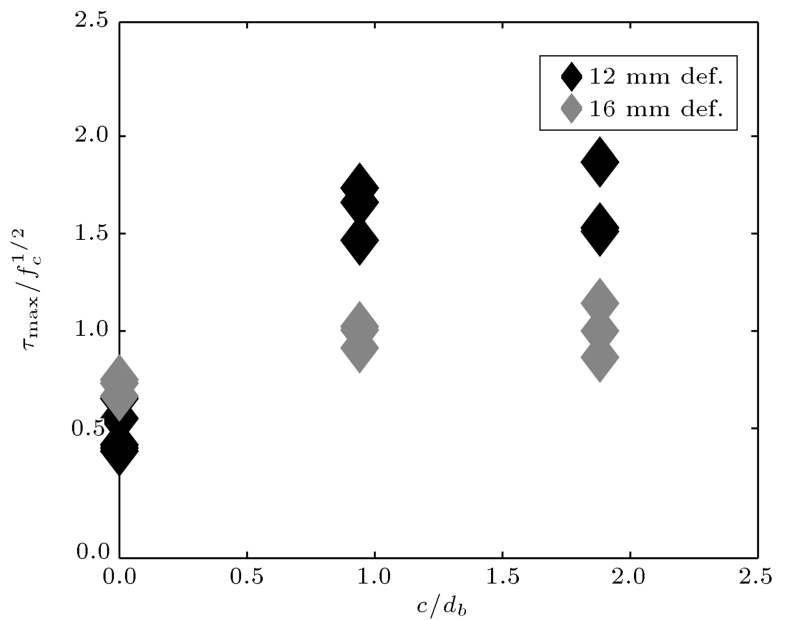

(a)

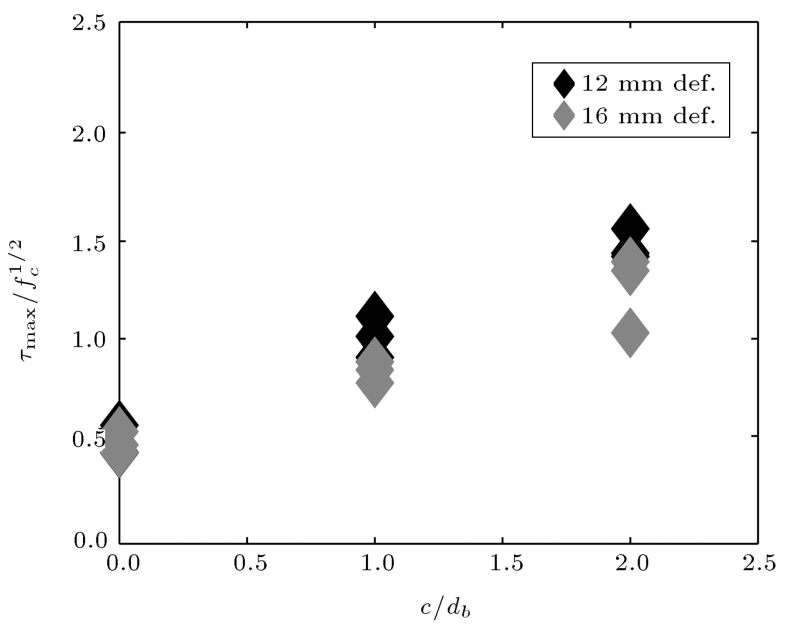

(b)

Figure 16. Normalized $\tau_{\max }$ of different bar types with varying covers: (a) Deformed and (b) plain (splitting specimens). 


\section{Development of bond strength relation}

Multi-variable nonlinear regression analysis is used to develop $\tau_{\max }$ models by using a suitable summation function for both pull-out and splitting failure modes. Variables such as concrete compressive strength $\left(f_{c}^{\prime}\right)$, development length $\left(L_{d}\right)$, cover $(\mathrm{c})$, diameter $\left(d_{b}\right)$, and bar type are included in $\tau_{\text {max }}$ models. The summation function of Orangun et al. [21] offers the best choice for use as an input function in the nonlinear regression analysis, since it includes all the important variables considered in the experimental work carried out by the authors. This function can be calibrated to prepare $\tau_{\max }$ equation for both pull-out and splitting bond failure modes.

The general form of the selected input functions for Orangun et al. [21] is given in Eq. (1):

$$
Y=(A+B w+C x) z^{D}
$$

where $A, B, C$, and $D$ are the parameter values determined through calibration, $Y$ is the dependent variable, and $w, x$, and $z$ are the independent variables.

\subsection{Regression analysis of $\tau_{\max }$ experimental data}

5.1.1. $\tau_{\max }$ equations for deformed bar's pull-out/splitting failure mode in LSC

To evaluate the general $\tau_{\max }$ equation for the pull-out and splitting failure mode of deformed bars, Eq. (1) was calibrated by conducting nonlinear regression analysis using the current experimental data, and the derived new parameter values are given in Eq. (2).

An additional dataset was selected from a report by Darwin et al. [22] in which an extended database from different studies was used to develop an expression for evaluating the splice strength and developing length regardless of the effect of transverse reinforcement. The specimens with concrete strength ranging between 15 and $21 \mathrm{MPa}$ were extracted from each dataset. The predominant failure mode in all these test data was splitting, and the beams were tested to evaluate the bond strength considering different parameters. It was observed from the data that large bar diameter and embedment lengths were used almost in all the specimens except for the Tepfers [23] dataset, including specimens with bar diameters 12,16 , and $19 \mathrm{~mm}$. Moreover, $c / d_{b}$ in the majority of the tests varied between 1 and 2 with very few specimens having $c / d_{b}$ ratio $>2$. Due to the variability in the experimental data from different sources, the error between predicted and experimental values was assumed to be normally distributed, and an uncertainty factor in accordance with $\pm 1 \sigma$ was evaluated. The resulting equation is given in Eq. (2) with an uncertainty factor of $\pm 2.1 \mathrm{MPa}$ :

$$
\begin{gathered}
\frac{\tau_{\max }}{f_{c}^{\prime} 0.68}=-0.048+0.22 \frac{c}{d_{b}}+3.22 \frac{d_{b}}{L_{d}} \pm 2.1 \\
R^{2}=0.72(\mathrm{MPa}) .
\end{gathered}
$$

The bond strength predictions $\left(\tau_{\max , p r e d}\right)$ from Eq. (2) are compared with the experimental bond strength values $\left(\tau_{\max , e x p}\right)$ in Figure $17(\mathrm{a})$. The upper and lower bounds were set to $\pm 1 \sigma \mathrm{MPa}$ to assess the percentage of data above and below this range. It was found that $15 \%$ of the data were out of this range. The frequency of ratio $\tau_{\max , \text { pred }} / \tau_{\max \text {,exp }}$ as a percentage of the total data is shown in Figure 17(b). For Eq. (2), a larger percentage ratio of ratios $\tau_{\max , p r e d} / \tau_{\max , \exp }$ was found to be close to one, as shown in Figure 17(b).

\subsection{2. $\tau_{\max }$ equation for plain bar's pull-out/splitting failure mode}

Eq. (1) is further calibrated for plain bars and the resulting equation is given as Eq. (3). The uncertainty factor for this equation is calculated to be \pm 0.96 :

$$
\begin{gathered}
\frac{\tau_{\max }}{\sqrt{f_{c}^{\prime}}}=0.253+0.1902 \frac{c}{d_{b}}+2.385 \frac{d_{b}}{L_{d}} \pm 0.96 \\
R^{2}=0.69(\mathrm{MPa}) .
\end{gathered}
$$

The predictions from Eq. (3) are compared with those of the experimental data in Figure 17(c). The frequency of ratio $\tau_{\max , \text { pred }} / \tau_{\max , \exp }$ as a percentage of total data is shown in Figure $17(\mathrm{~d}) .19 \%$ of the data were found to be out of the set bound for the plain bar's bond strength.

In the current study, the concrete strength power factors of 0.68 and 0.5 are evaluated for deformed, cold formed, and plain bar. This suggests large dependency of concrete strength on bond strength for deformed and cold formed bars as compared to plain bars. In bond strength equation of Orungun et al., $\tau_{\max }$ is normalized with respect to $\sqrt{f_{c}^{\prime}}$ to represent the effect of $f_{c}^{\prime}$ (or the tensile strength) on the bond strength. However, Zuo and Darwin [24] suggested that normalization using $\sqrt{f_{c}^{\prime}}$ overestimates bond strength for the HSC and underestimates bond strength for NSC. $f_{c}^{\prime 1 / 4}$ was found to have a better correlation with bond strength for all ranges of concrete strength.

\section{Conclusions}

Due to the large number of NERC structures in the building stock of developing countries, it is important to investigate the effect of different deficient parameters on bond characteristics for more reliable seismic vulnerability assessment:

a. Among the investigated parameters, low strength concrete and concrete cover have more influence on 


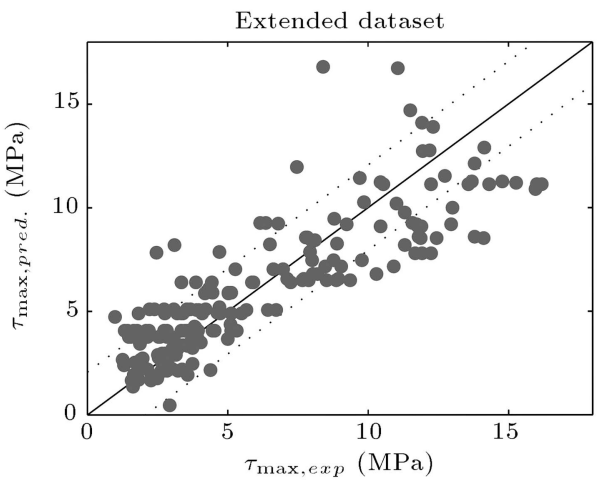

(a)

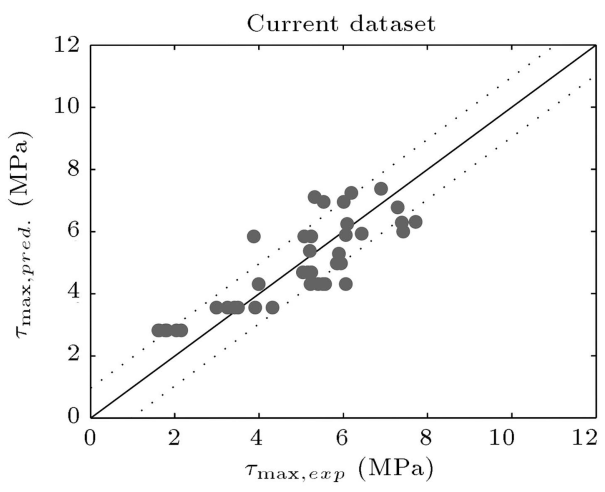

(c)

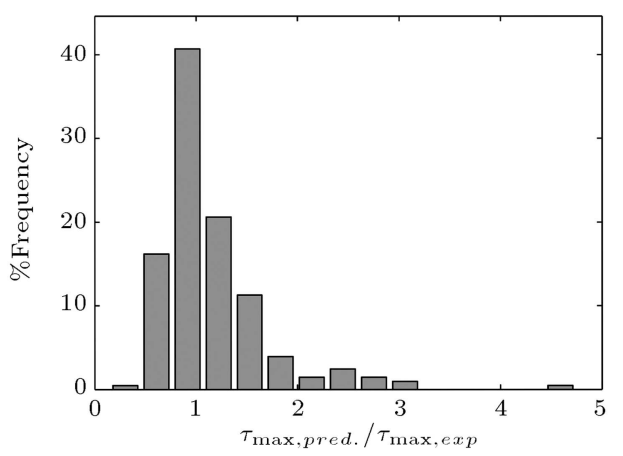

(b)

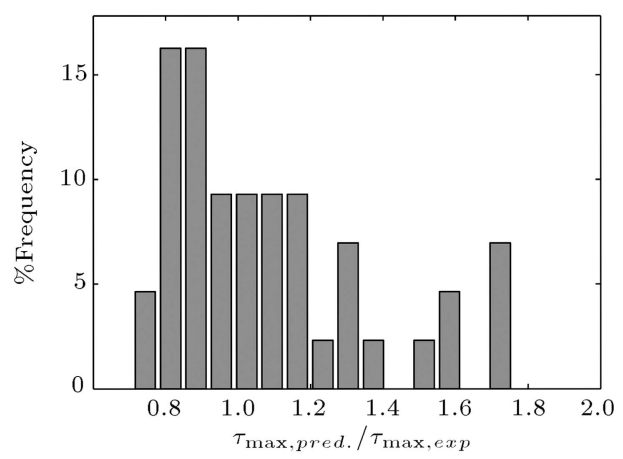

(d)

Figure 17. Assessment of different bars bond strength model: (a) Scatter between deformed bar $\tau_{\max }$ experimental and predicted results, (b) \% frequency of deformed bar $\tau_{\max }$ normalized data, (c) scatter between plain bar $\tau_{\max }$ experimental and predicted results, (d) \% frequency of plain bar $\tau_{\max }$ normalized data.

the bond strength. For the deformed bar specimens with concrete strength of around $10 \mathrm{MPa}$, the pullout bond strength $(1.98 \mathrm{MPa})$ is almost half the bond strength of specimens with relatively higher concrete strength (15-20 MPa). Hence, NERC structures with concrete strength of around $10 \mathrm{MPa}$ are expected to have larger slip deformations and brittle failures due to lower bond strength;

b. The specimens with a very small cover (i.e., $c=$ 0 ), in an exposed bar condition, have very low splitting bond strength $(0.46 \mathrm{Mpa})$ and indicate high vulnerability of inferior quality structures with exposed bars;

c. The plain bars do not show the evidence of splitting in most of the specimens. However, the cover still appears to have effect due to the additional confinement. Nonetheless, plain bars fail at a lower strength and have inferior post-peak characteristics;

d. The data from this experimental study are used to develop the bond strength models for different bar types in LSC. The bond strength models from the summation equations are, therefore, proposed to predict both the splitting and pull-out behaviours of low strength structures. The summation function accounts for all the studied parameters, and the bond strength for pull-out and splitting bond failure modes is predicted reasonably well using the developed equation. These equations can be also used in defining $\tau-s$ behaviour;

e. The higher power factor of 0.68 for concrete strength is evaluated for deformed bars as compared to the traditional value of 0.5 . This indicates larger influence of low strength concrete on bond strength of deformed as compared to normal and high strength concretes.

\section{Acknowledgement}

The first author acknowledges the financial support provided by the Higher Education Commission (HEC), Pakistan, to conduct this research as a part of his $\mathrm{PhD}$ work, which developed an analytical seismic vulnerability assessment framework for reinforced concrete structures in developing countries.

\section{Nomenclature}

$E_{s} \quad$ Modulus of elasticity of steel

$f_{c}^{\prime} \quad$ Concrete compressive strength

$f_{c t} \quad$ Concrete tensile strength 


$\begin{array}{ll}\tau_{\max } & \text { Bond strength } \\ L_{d} & \text { Development length } \\ c & \text { Concrete cover } \\ d_{b} & \text { Bar diameter } \\ h & \text { Rib height of rebar } \\ s & \text { Rib spacing of rebar } \\ \mu & \text { Mean } \\ \sigma & \text { Standard deviation } \\ \text { LSC } & \text { Low Strength Concrete } \\ \text { NERC } & \text { Non-Engineered Reinforced Concrete } \\ \text { RC } & \text { Reinforced Concrete }\end{array}$

\section{References}

1. Naseer, A. Ali, S.M. and Hussain, Z. "Reconnaissance report on the 8th October, 2005 earthquake Pakistan", Earthquake Engineering Centre, Department of Civil Engineering NWFP UET Peshawar, Pakistan (2006).

2. Duranni, A.J., Elnashai, A.S., Hashash, Y.M.A., Kim, S.J., and Masud, A. "The Kashmir earthquake of October 8, 2005, A quick look report", Mid- America Earthquake Center, University of Illinois at UrbanaChampaign (2005).

3. Nisikawa, T., Nakano, Y., Tsuchiya, Y., Sanada, Y., and Sameshima, H. "Quick report of damage investigation on buildings and houses due to October 8, 2005 Pakistan earthquake", Japan Society of Civil Engineers (JSCE) and Architectural Institute of Japan (AIJ) (2005).

4. Peiris, N., Rossetto, T., Burton, P., and Mahmood, S. "EEFIT mission: October 8, 2005 Kashmir Earthquake" (2005).

5. Bal, I.E., Crowley, H., Pinho, R.F., and Gulay, F.G. "Detailed assessment of structural characteristics of Turkish RC building stock for loss assessment models", Soil Dynamics and Earthquake Engineering, 28(10), pp. 914-932 (2008).

6. Hong, C. and Araki, H. "Bond characteristics between low strength concrete and plain round bar under reversal loading", 15th WCEE, Lisboa (2012)

7. Ahmad, S., Assessment of Damages Caused to Structures Due to October 8th, 2005 Kashmir Earthquake, Pakistan, The University of Sheffield (2007). https://www.sheffield.ac.uk/polopoly_fs/1.107463!/ file/Ahmad-Survey.pdf

8. Chaudat, T., Garnier, C., Cvejic, S., Poupin, S., LeCorre, M., and Mahe, M. "Seismic tests on a reinforced concrete bare frame with FRP retrofittingtests report ecoleader project no 2", CEA Internal Report 05-006/A (2005).

9. Pinho, R. and Elnashai, A.S. "Dynamic collapse testing of full scale four storey RC frame", ISET Journal of Earthquake Technology, Paper No. 406, 37(4), pp. 143-163 (2000)
10. ACI408R-03 "Bond and development of straight reinforcing bars in tension", American Concrete Institute (2003).

11. ACI408.2 "Bond under cyclic loading", Technical Report. American Concrete Institute (2005).

12. Kyriakides, N., Seismic Vulnerability Assessment of $R C$ Buildings and Risk Assessment for Cyprus, The University of Sheffield (2008).

13. Mohamad, A.Z. and Clark, L.A. "Bond behaviour of low-strength concrete", Mangzine of Concrete Research, 44(160), pp. 195-203 (1992).

14. Feldman, L.R. and Bartlett, F.M. "Bond strength variability in pullout specimens with plain reinforcement", ACI Structural Journal, 102(6), pp. 860-867 (2005).

15. Bedirhanoglu, L., Iiki, A., Pujol, S., and Kumbassar, N. "Behaviour of deficient joints with plain bars and low strength concrete", ACI Structural Journal, 107(3), pp. 300-310 (2010).

16. Ahmad, S. "Seismic vulnerability of non-ductile reinforced concrete structures in developing countries", Ph.D. Thesis, The University of Sheffield, U.K. (2011).

17. Ahmad, S., Rafi, M.M., Pilakoutas, K., Khan, Q.U.Z., Shabbir, F., and Tahir M.F. "Bond-slip Behaviour of steel bars in low-strength concrete", Institute of Civil Engineers, Structures and Buildings, 169(7), pp. 524537 (2016).

18. BS1881-121 "Testing concrete - Part 121: Method for determination of static modulus of elasticity in compression" (1983).

19. BS:EN12390-6 "Testing hardened concrete - Part 6: Tensile splitting strength of test specimens" (2000).

20. RILEM/CEB/FIP Recommendation RC 6 "Bond test for reinforcing steel: Pullout test" (1978).

21. Orangun, C.O., Jirsa, J.O., and Breen, J.E. "The strength of anchored bars: a re-evaluation of test data on development length and splices", Research Report No.154-3F, Center For Highway Research, The University Of Texas At Austin (1975).

22. Darwin, D., Mccabe, S.L., Idun, E.K., and Schoenekase, S.P. "Development length criteria: bars without transverse reinforcement", The Civil Engineering Research Foundation Contract No 91-N6002 The National Science Foundation, Research Grant No. MSM-9021066, The Reinforced Concrete Research Council, Project 56 (1992).

23. Tepfers, R. "A theory of bond applied to overlapped tensile reinforcement splices for deformed bars", Publ 73:2. Division of Concrete Structures, Chalmers University of Technology, Goteborg, p. 328, Doktorsavhandling (1973).

24. Zuo, J. and Darwin, D. "Splice strength of conventional and high relative rib area bars in normal and high-strength concrete", ACI Structural Journal, 97(4), pp. 630-641 (2000). 


\section{Biographies}

Sohaib Ahmad has diverse Civil/Structural Engineering and research experience. He is experienced in structural analysis, design and assessment of commercial and industrial buildings. He has conducted analytical and empirical seismic safety assessment and retrofitting of existing structures. Moreover, he has done design reviews, condition assessment, visual inspections, and retrofitting works.

Dr. Ahmad's PhD is related to development of a probabilistic analytical framework for seismic vulnerability assessment of low strength reinforced concrete structures of developing countries. He has several publications in reputed international journals and has presented research papers, posters in various conferences. He has supervised/co-supervised several research projects at Masters and $\mathrm{PhD}$ levels. His research interests include concrete material, seismic fragility and risk analysis of buildings and bridges, seismic retrofitting using FRP, structural health monitoring, aging of structures.

Kypros Pilakoutas is a Professor of Construction Innovation at the Department of Civil and Structural Engineering in The University of Sheffield, U.K. He is the Manager of the Centre for Cement and Concrete and the Chairman of the Concrete and Earthquake Engineering Research Group. Professor Pilakoutas is with the Departmental Commercialization Champion and is a Director of two technology spin-out companies. He has vast experience in managing European Research Networks and has had more than 10 EU grants. He has a large number of international contacts and leads or has participated in several international committees in his research fields. Professor Pilakoutas has been recently awarded an EU FP6 grant of 1,700,000 to investigate "Economical and Sustainable Pavement Infrastructure for Surface Transport". He has over 30 patents awarded worldwide. Two of his patents are commercially exploited worldwide. Two more patents' applications have been made in the field of using wire from recycled tyres as reinforcement. His research is in the fields of structural concrete, FRP and fibre reinforcement, repair, construction innovation and earthquake engineering. Professor Pilakoutus has various publications in well-reputed international journals. He also has won various awards and honours.

Muhammad Masood Rafi is a Professor and Chairman in the Department of Earthquake Engineering at NED University of Engineering and Technology, Pakistan. His research interests include behaviour of FRP reinforced concrete structures, finite-element analysis of RC structures, fire resistance of concrete structures, deflection of concrete structures, experimental analysis of RC structures, recycling of concrete, and seismic analysis and retrofitting of reinforced concrete and masonry structures. Professor Rafi is the Editor-inChief of the NED University Journal of Research. He is also a member of the Editorial Board for Journal of Structural Fire Engineering and Frontiers in Built Environment.

Qaiser Uz Zaman Khan has diverse research and academic experience and has worked in various capacities (teaching, research, laboratory, administration, consultant, etc.) at the Department of Civil Engineering, UET Taxila. He is also a member of various technical committees. His research interests include concrete material, seismic fragility and risk analysis of buildings and bridges, seismic retrofitting using FRP, structural health monitoring. Professor Qaiser has various publications in well-reputed international journals. He also has won various awards and honours.

Kyriacos Neocleous is a researcher at the Department of Civil and Geomatics Engineering of the Cyprus University of Technology. He has more than 12 years of research experience in the field of structural engineering, structural concrete, novel concrete reinforcements as well as testing techniques for concrete and reinforcement. Previously, he held the position of Senior Research Fellow in the University of Sheffield, U.K. Dr. Neocleous has various publications in wellreputed international journals. He also has won various awards and honours. 